\title{
Emprego integrado de métodos sísmicos e geoelétricos no estudo de barragens de terra de pequeno porte
}

Walter Malagutti Filho, Depto. de Geologia Aplicada - IGCE-Unesp

Cesar Augusto Moreira*, Depto. de Geologia Aplicada - IGCE-Unesp

João Carlos Dourado, Depto. de Geologia Aplicada - IGCE-Unesp

Marina Mendes Coura, mestranda em Geociências e Meio Ambiente, IGCE-Unesp

Leonides Guireli Netto, pós-graduando do Instituto de Pesquisas Tecnológicas do Estado de São Paulo - IPT

Copyright 2018, SBGf - Sociedade Brasileira de Geofísica

Este texto foi preparado para a apresentação no VIII Simpósio Brasileiro de Geofísica, Salinópolis, 18 a 20 de setembro de 2018. Seu conteúdo foi revisado pelo Comitê Técnico do VIII SimBGf, mas não necessariamente representa a opinião da SBGf ou de seus associados. E proibida a reprodução total ou parcial deste material para propósitos comerciais sem prévia autorização da SBGt.

\begin{abstract}
Small dams are used mainly by cities, industries, mines and agro-industries as a means to discipline the use of water, for diverse purposes. This kind of construction is often built by farmers or city halls, which do not possess the appropriate resources to conduct a proper project. In addition, the need for constant monitoring and maintenance of this kind of structure is essential to guarantee its integrity, detect fractures, infiltrations, or leaks, and therefore helps preventing accidents of catastrophic proportions. This paper presents the results of seismic refraction, electrical resistivity tomography and self-potential methods, performed in an integrated manner, on two earthfill dams, located in the cities of Cordeirópolis and Ipeúna, inland São Paulo state, Brazil. The objective was to aknowledge the geophysical signature to infer geotechnical and hydrogeological parameters such as bedrock, layers thickness and disposition, possible weak spots in the bodies of the two earthfill dams as well as ground water preferential flow inside them.
\end{abstract}

\section{Introdução}

Pequenas barragens são utilizadas por municípios, agroindústrias, minerações e indústrias de médio a grande porte, com o objetivo de disciplinar o uso da água. Esse tipo de obra, em função de sua pequena dimensão é, muitas vezes, executada por proprietários rurais ou prefeituras de pequenas cidades e não pode depender de grandes orçamentos carecendo, muitas vezes, de projetos apropriados. Além disso, o necessário e constante monitoramento e manutenção desse tipo de estrutura é fundamental para garantir a sua integridade, detectar fissuras, infiltrações, vazamentos, etc...e prevenir, portanto, eventuais acidentes, que possam vir a ter dimensões catastróficas.

No presente trabalho, são mostrados resultados de um estudo geofísico desenvolvido em duas barragens de terra, de pequeno porte, situadas nos municípios paulistas de Cordeirópolis e Ipeúna. O objetivo principal e geral do estudo é o conhecimento da assinatura geofísica, obtida com métodos sísmicos e geoelétricos, empregando técnicas de aquisição e processamento tomográfico, de maneira integrada e nos mesmos locais, para inferir parâmetros geotécnicos, tais como, embasamento, zoneamento da estrutura, espessura e eventuais zonas de fraqueza no corpo de duas barragens de terra. A existência de tais zonas seria evidenciada por eventuais infiltrações e/ou percolação de água nos barramentos. O principal produto esperado é um roteiro de estudos, que contemple o emprego dos métodos geofísicos de forma integrada, para o fornecimento de um diagnóstico expedito e de baixo custo, acerca da integridade de pequenas barragens, visando orientar e aperfeiçoar posteriores investigações diretas.

\section{Metodologia / Problema Investigado}

O estudo é realizado em duas barragens de terra, de pequeno porte, localizadas no interior do estado de São Paulo. As barragens encontram-se em zonas rurais dos municípios de Cordeirópolis-SP e Ipeúna-SP (Figura 1). A região de estudo, está inserida na Bacia Sedimentar do Paraná, localizada no centro-leste da América do Sul. Uma das áreas - município de Cordeirópolis - encontrase sobre litologia clássica da Formação Serra Geral, constituída por rochas vulcânicas básicas toleíticas, de coloração preta a cinza esbranquiçada, com camadas delgadas de rochas constituídas por arenitos entre derrames (ZAINE, 1994). Soleiras e diques ocorrem associados aos derrames basálticos. A barragem de Ipeúna assenta-se sobre rochas sedimentares do Grupo Itararé, que constituem a unidade basal da sequência permo-carbonífera da Bacia do Paraná, aflorando em áreas de fundo de vales dos rios da região. $\mathrm{Na}$ área da pesquisa, o Grupo Itararé é limitado na base pelo contato com rochas cristalinas pré-silurianas, enquanto o contato superior se dá com a Formação Tatuí, de forma discordante.

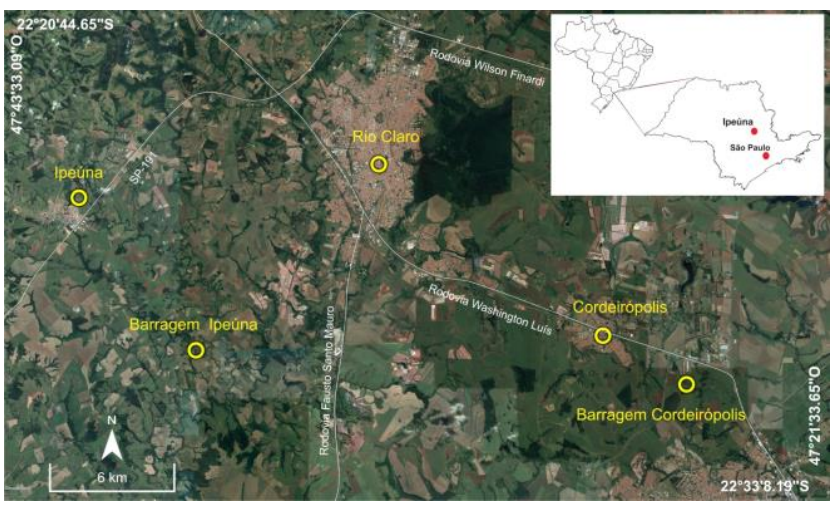

Figura 1 - Mapa de localização das barragens. 
As pesquisas priorizaram o emprego do método sísmico da refração (com aquisição e processamento tomográfico) e também de métodos geoelétricos, através das técnicas do Imageamento Elétrico (IE) - com medidas da resistividade e da polarização induzida - e potencial espontâneo (SP).

Por se tratar de estudo metodológico e comparativo, a escolha das áreas, nas quais as barragens situam-se, foi norteada pelos seguintes critérios: dimensões parecidas (ambas de pequeno porte), diferença entre as litologias que compõe a estrutura dos barramentos e sua base, além de critérios logísticos, pois ambas as barragens possuem um fácil acesso, permitindo a realização de diversos ensaios geofísicos de forma semi-continuada.

Os ensaios do IE objetivaram a aquisição de dados de eletrorresistividade e de cargabilidade em duas linhas de investigação, localizadas no eixo de cada barragem (Figuras 2 e 3) utilizando-se os arranjos de eletrodos Wenner, Schlumberger, Dipolo-Dipolo na forma de aquisição tomográfica multi-eletródica (MOREIRA et. al., 2018), com espaçamento entre os eletrodos de 2 metros. $O$ equipamento utilizado foi o resistivímetro $A B E M$ Terrameter LS de 84 canais, do Laboratório de Geofísica do Depto. de Geologia Aplicada - Unesp, devidamente configurado para efetuar conjuntamente as medidas de resistividade elétrica e de cargabilidade usadas nesse estudo

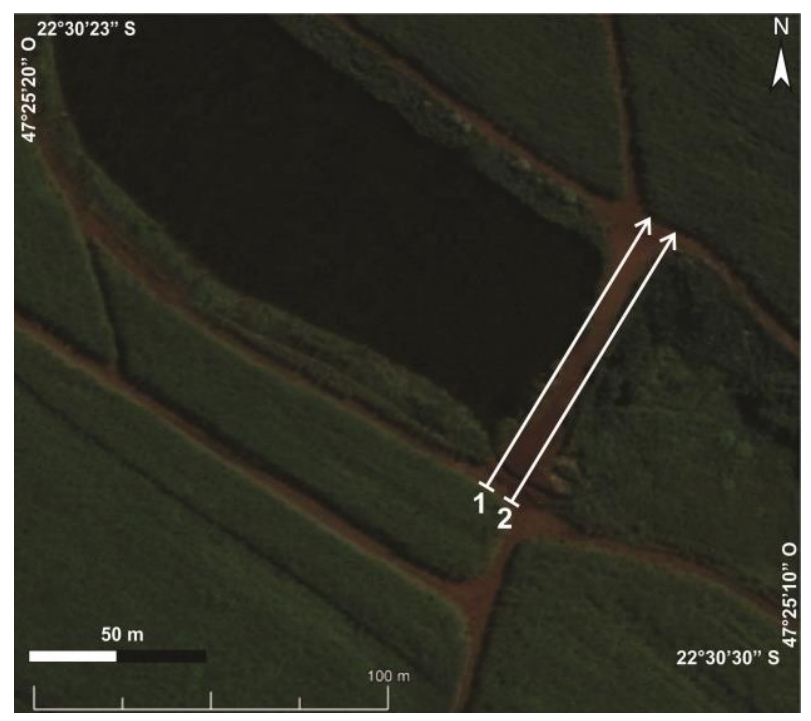

Figura 2 - Localização das linhas de ensaios elétricos e sísmicos - Barragem de Cordeirópolis

O método do potencial espontâneo foi executado utilizando-se a Técnica dos Potenciais, ou base fixa (GALLAS, 2000). Os ensaios foram realizados ao longo de três linhas dispostas paralelamente e separadas de dois metros entre si, em ambas as áreas; essa foi também a distância entre os eletrodos de medida, ao longo das linhas. O equipamento utilizado foi o módulo receptor do resistivímetro BISON 2390, configurado para efetuar leituras de potenciais de até $1999 \mathrm{mV}$.

O emprego do método sísmico, comtemplou a técnica da sísmica de refração, com a aquisição e processamento tomográfico (SHEEHAN et al., 2005). As medidas foram obtidas com o sismógrafo SUMMIT X Stream Pro da DMT, utilizando geofones de $100 \mathrm{~Hz}$, para o registro das ondas refratadas longitudinais. O espaçamento entre os sensores foi de 2 metros e as linhas de aquisição foram as mesmas usadas nos levantamentos geoelétricos mostradas nas Figuras 2 e 3, já referidas. A fonte de ondas sísmicas empregada foi o martelo sísmico, impactado sobre placa de aço no solo.

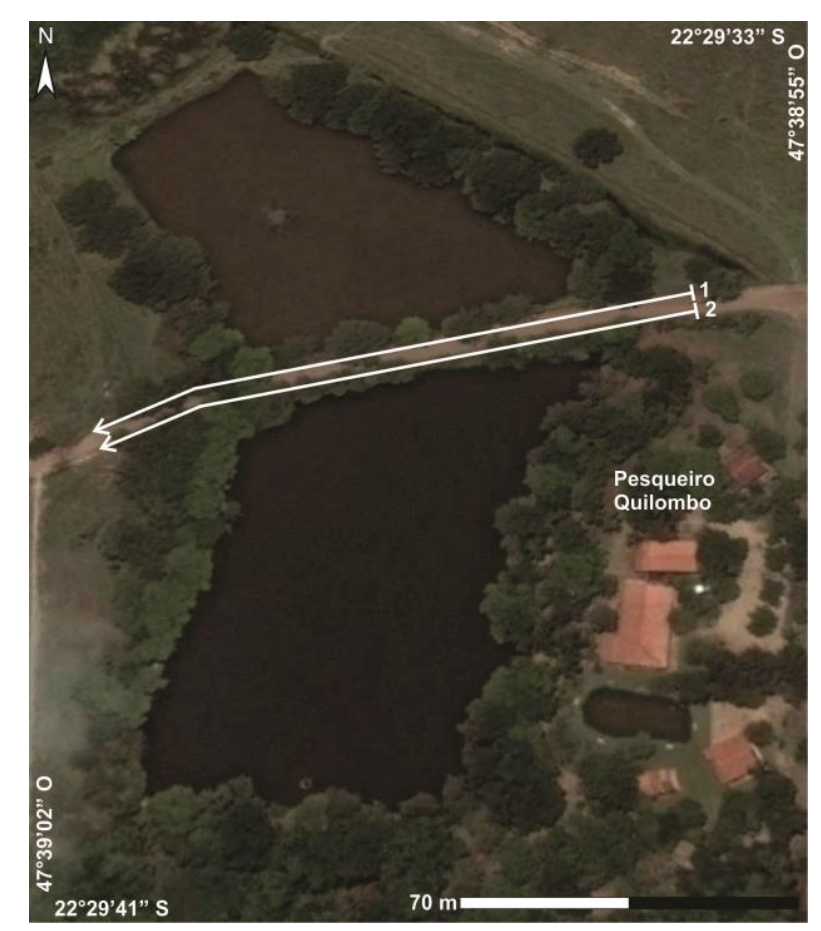

Figura 3 - Localização das linhas de ensaios elétricos e sísmicos - Barragem de Ipeúna.

\section{Resultados}

Os resultados dos ensaios do Potencial Espontâneo são mostrados Figuras 4 e 5, na forma de mapas de variação do SP, respectivamente, nas barragens de Cordeirópolis e Ipeúna.

Os dados do Imageamento Elétrico foram submetidos a uma modelagem 2D, por meio do software Res2Dinv, cujas seções foram calculadas, por inversão, a partir das pseudo-seções adquiridas. Nas Figuras 6 e 7 são mostradas seções típicas, de ambas as áreas, com os dois parâmetros físicos medidos.

Nas Figuras 8 e 9 são mostrados, respectivamente, os gráficos tempo x distância e o modelo sísmico final da linha 1, calculado com o emprego do software Seislmager, na barragem de Cordeirópolis. 


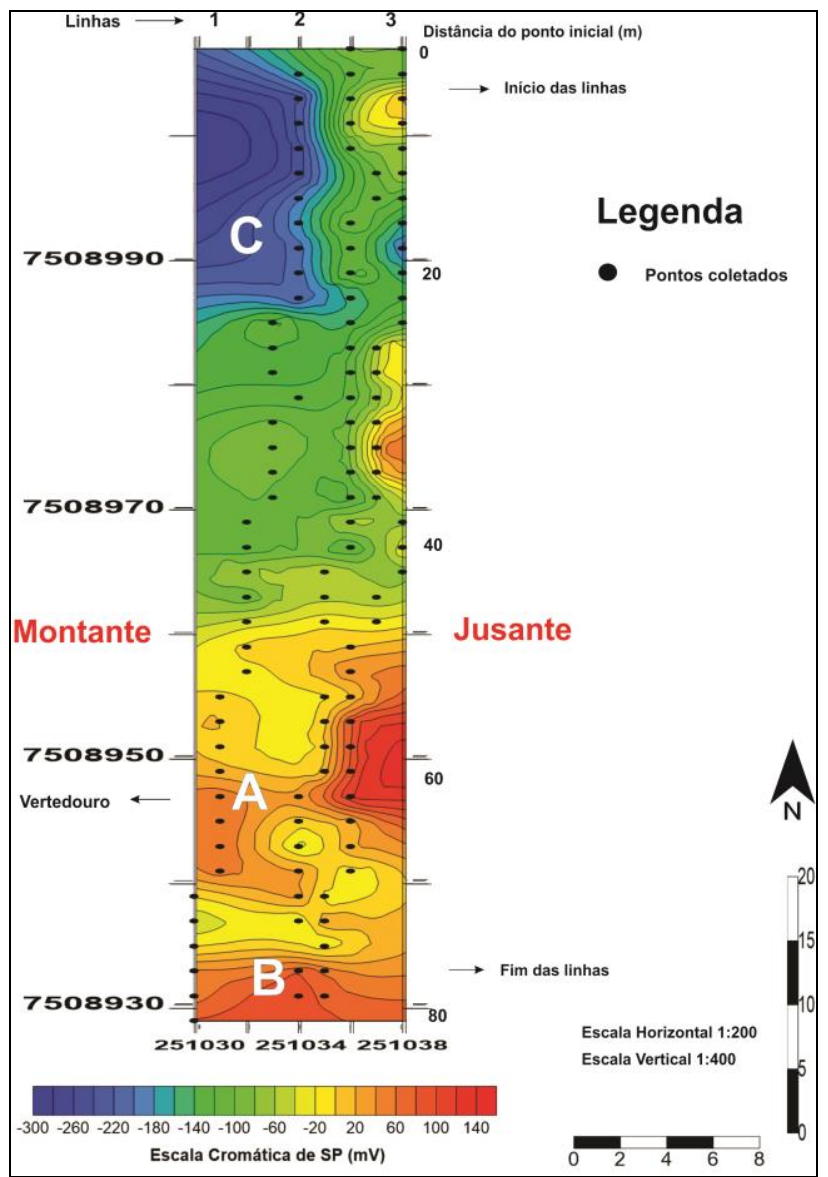

Figura 4 - Mapa de variação do potencial espontâneo da barragem de Cordeirópolis

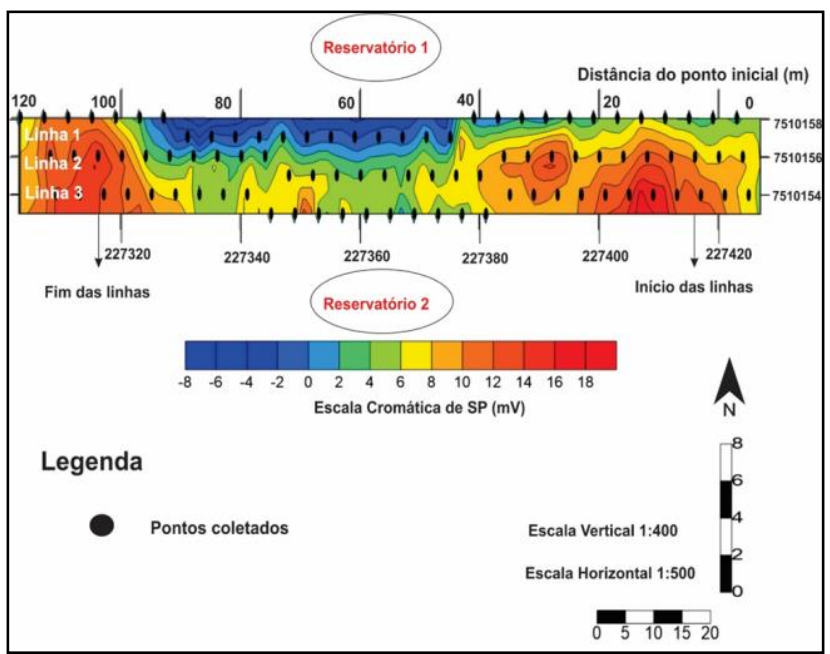

Figura 5 - Mapa de variação do potencial espontâneo na barragem de Ipeúna

\section{Discussões e Conclusão}

Os resultados obtidos com o método do SP, como esperado, apresentaram informações sobre o fluxo da água subterrânea e suas relações com zonas de maior infiltração e suas relações preferenciais. Essas informações ficaram bastante claras em ambas as áreas: na barragem de Ipeúna os dados de SP mostraram com boa precisão os limites da estrutura e na barragem de Cordeirópolis, além de indicar o fluxo preferencial, apontou a presença - e continuidade - de um vertedouro situado ao sul da estrutura.

Os modelos de inversão de resistividade elétrica, da barragem de Cordeirópolis, (Figura 6) revelam a

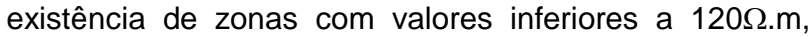
possivelmente relacionados a infiltração de água acumulada a montante do barramento. Observa-se ainda uma clara estratificação dos dados, com valores inferiores a $600 \Omega \mathrm{m}$ nos primeiros $10 \mathrm{~m}$ de profundidade e com aumento significativo abaixo desta profundidade, superiores a $3000 \Omega$.m. A camada superior relaciona-se ao solo e blocos de rocha que formam o barramento, ao passo que a camada inferior, de alta resistividade, reflete o embasamento rochoso: rocha intrusiva básica. A aparente discrepância de posição entre a zona de potencial elétrico negativo e a zona de baixa resistividade é atribuída a diferenças no comprimento das linhas de aquisição e posicionamento inicial dos ensaios. O ensaio de SP teve seu início deslocado de $10 \mathrm{~m}$ do início da linha de IE, portanto, é possível reconhecer a coincidência de áreas anômalas. Os dados de cargabilidade para esta barragem apresentam aumento de valores concomitante com o aumento da profundidade estratificados em duas camadas distintas: a primeira limitada aos primeiros $8 \mathrm{~m}$ de profundidade e com até $4 \mathrm{mV} / \mathrm{V}$, sobreposta a segunda, com valores entre $4 \mathrm{mV} / \mathrm{V}$ e $10 \mathrm{mV} / \mathrm{V}$, interface aproximada de contato barragem/embasamento.

Os resultados do IE, para a barragem de Ipeúna (Figura 7), revelam uma ampla área com valores de resistividade inferiores a $50 \Omega$.m desde posições rasas até a base do modelo de inversão, lateralmente acompanhado por uma faixa de valores entre $50 \Omega . m$ e $250 \Omega$.m. O substrato é composto por arenitos do Grupo Itararé que apresentam variações faciológicas entre siltito a arenito fino. Aparentemente a faixa de arenitos finos saturados é relacionada aos valores superiores a $50 \Omega$.m, que lateralmente gradam para siltitos saturados no sentido do final da seção. Os dados de SP, nessa barragem, apresentam uma faixa com valores pouco negativos entre $40 \mathrm{~m}$ e $100 \mathrm{~m}$ em contato com o reservatório. Neste intervalo de distância há uma variação significativa de valores de resistividade e, portanto, não é reconhecível uma zona de infiltração correspondente, no eixo do barramento. De qualquer forma, entre $40 \mathrm{~m}$ e $100 \mathrm{~m}$ ocorrem zonas com valores de resistividade superiores a $500 \Omega$.m, que podem ser relacionados não somente à saturação, mas também ao fluxo em arenitos no sentido transversal ao eixo de barramento.

O método sísmico da refração, na modalidade de aquisição e processamento tomográfico, constitui-se num poderoso instrumento para o zoneamento geotécnico e 
posicionamento em subsuperfície de diferentes estratos, refletindo a sua compacidade e eventual conteúdo de água. No caso desse trabalho, pode-se notar, na seção apresentada na Figura 9, que o solo superficial é bem delimitado, pelos valores de velocidade até $0,6 \mathrm{Km} / \mathrm{s}$; é seguido por uma camada de maior velocidade - (até 1,3 $\mathrm{Km} / \mathrm{s}$ ) - provável saprólito - que estaria saturado a partir da profundidade de 4 metros (velocidades de $1,5 \mathrm{Km} / \mathrm{s}$ ). $O$ topo do maciço são relaciona-se com os valores maiores do que $3,0 \mathrm{Km} / \mathrm{s}$.

O presente estudo é parte de um projeto amplo que visa conhecer a assinatura geofísica de barragens de terra sobre diferentes litologias. Dessa forma, recomenda-se o emprego de outros métodos, tais como a análise da dispersão de ondas superficiais, no procedimento de Multichannel Analysis of Surface Waves (MASW) e a sísmica de refração com a onda $S$, a serem executados nessa pesquisa e cujos resultados serão comparados e integrados aos já adquiridos. No entanto os produtos obtidos e ora apresentados, permitem concluir pela importância do emprego integrado dos diferentes métodos no estudo da integridade de barragens de terra, de pequeno porte.

\section{Agradecimentos}

Os autores agradecem a Fundação de Amparo à Pesquisa do Estado de São Paulo que, através do Processo 2016/18080-9, financia essa pesquisa.

\section{Referências}

GALLAS, J. D. F. - 2000 - Principais métodos geoelétricos e suas aplicações em prospecção mineral, hidrogeologia, geologia de engenharia e geologia ambiental. Tese de Doutorado em Geociências e Meio Ambiente - Instituto de Geociências e Ciências Exatas, Universidade Estadual Paulista, $174 \mathrm{p}$.

MOREIRA, C.A., HELENE, L.P.I., NOGARA, P., ILHA, L.M. 2018. Analysis of leaks from geomembrane in a sanitary landfill through models of electrical resistivity tomography in South Brazil. Environmental Earth Sciences, 77(7).

SHEEHAM, J. R.; DOLL, W. E. \& MANDELL, W. A. 2005 - An Evaluation of Methods and Available Software for Seismic Refraction Tomography Analysis. JEEG, Volume 10, Issue 1, pp. 21-34

ZAINE, J. E. - 1994 - Geologia da Formação Rio Claro na folha Rio Claro (SP). Dissertação de Mestrado Instituto de Geociências e Ciências Exatas, Universidade Estadual Paulista, $174 \mathrm{p}$. 


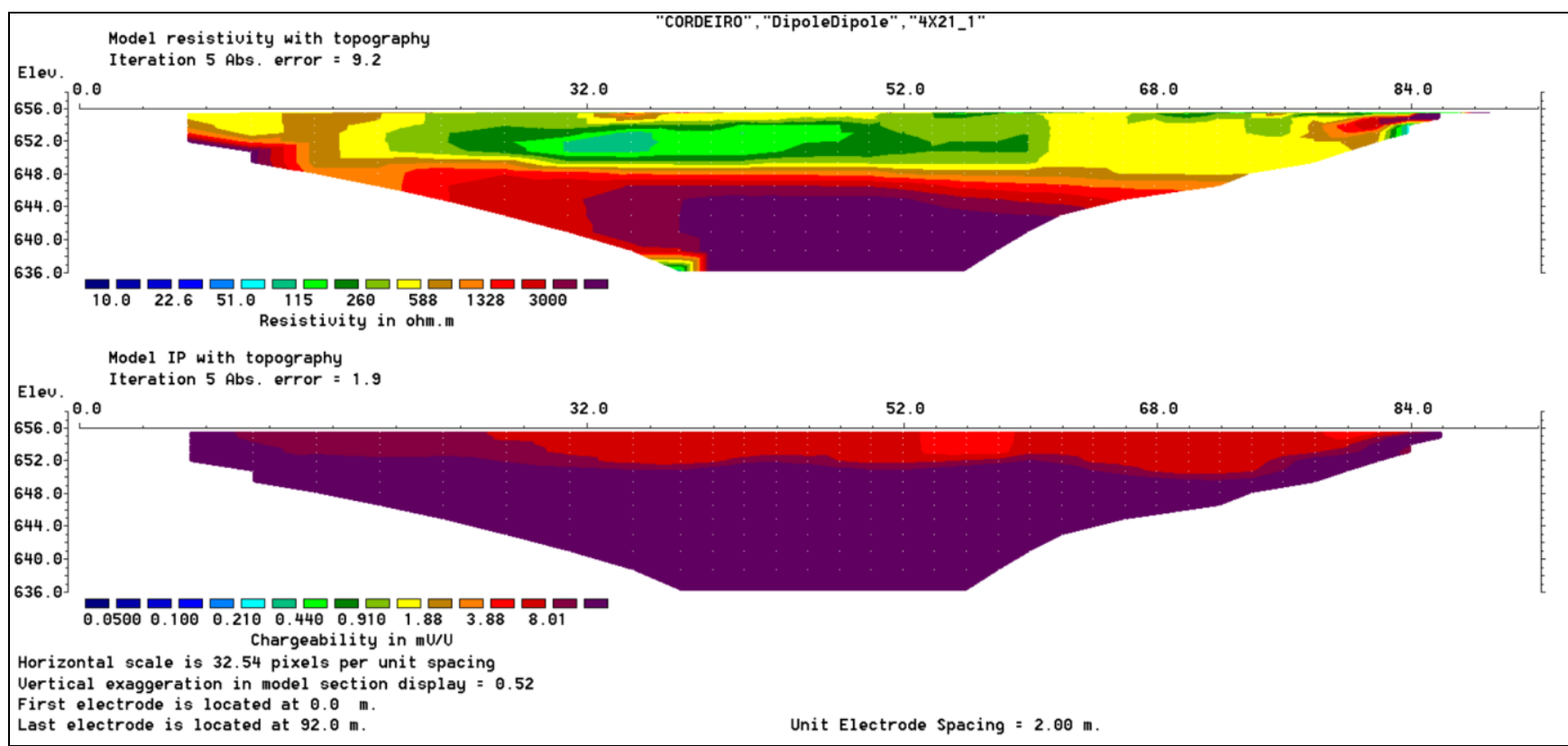

Figura 6: Seções geoelétricas obtidas com o arranjo Dipolo-dipolo - Linha 01, Barragem de Cordeirópolis, com resistividade elétrica acima e cargabilidade abaixo.

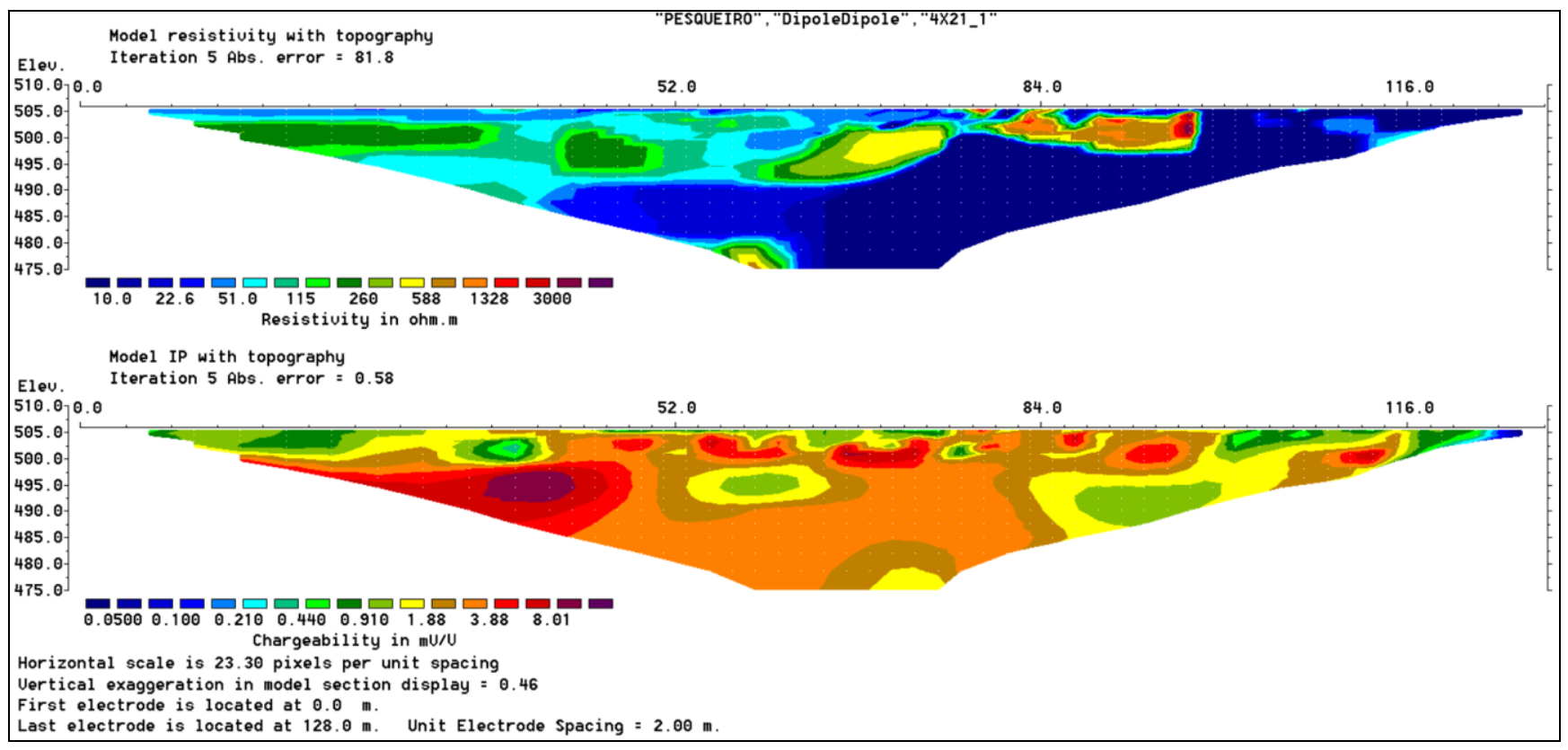

Figura 7: Seções geoelétricas obtidas com o arranjo Wenner na Linha 01, Barragem de Ipeúna, com resistividade elétrica acima e cargabilidade abaixo. 


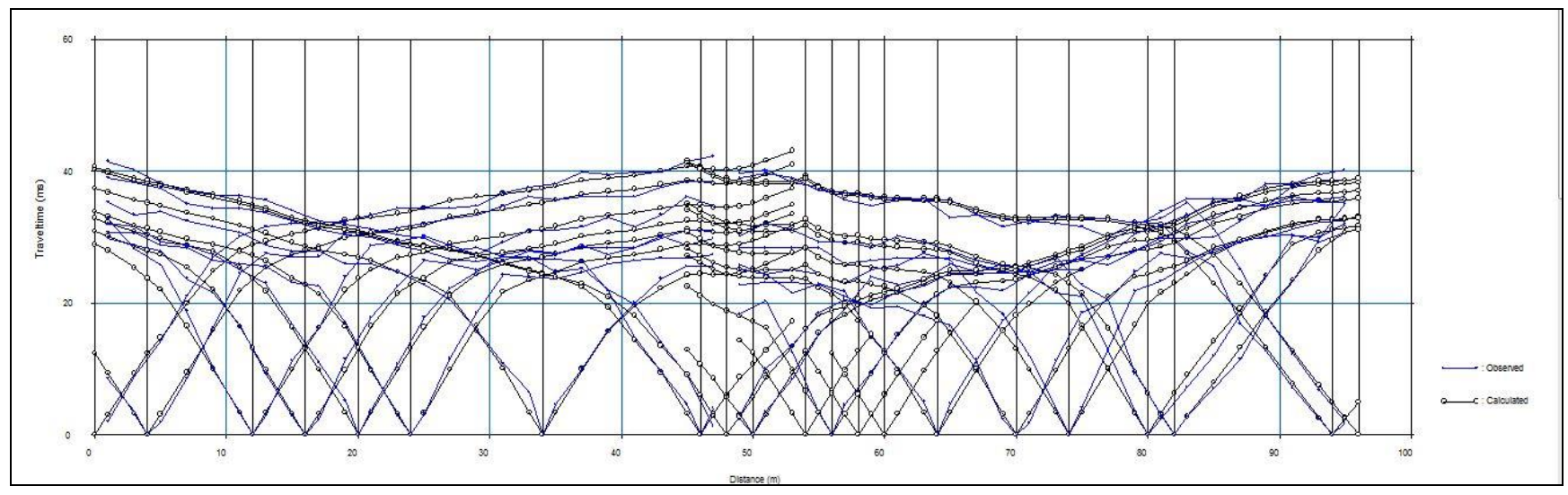

Figura 8-Gráficos tempo x distância - Linha 01, Barragem de Cordeirópolis

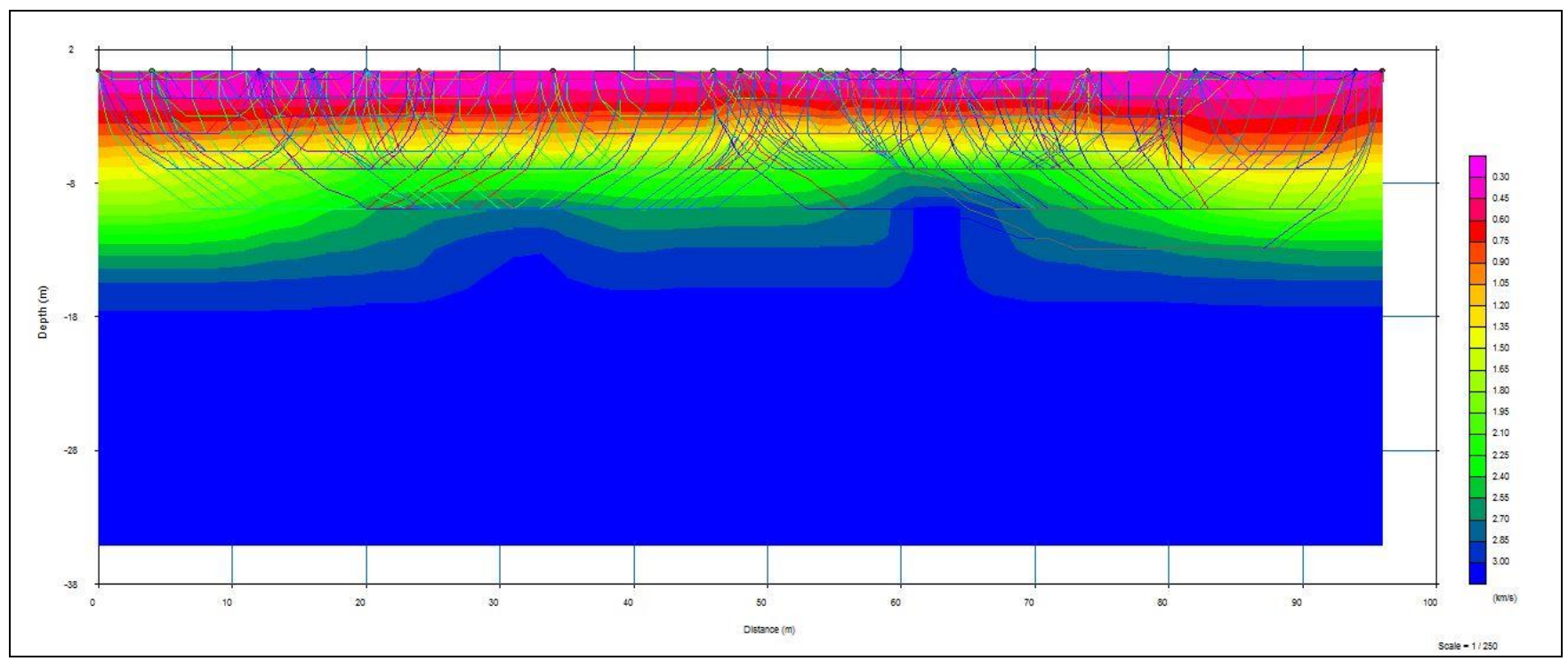

Figura 9 - Seção sísmica, Linha 01, Barragem de Cordeirópolis 